\title{
O LÚDICO COMO FORMA DE TRABALHAR AS INTELIGÊNCIAS MÚLTIPLAS: UM ESTUDO DE CASO COM CRIANÇAS E ADOLESCENTES MORADORES DE ÁREA DE VULNERABILIDADE SOCIAL
}

\section{ARTIGO ORIGINAL}

VIVONI, Sandra Mara Nunes ${ }^{1}$, VIVONI, Gabriela Nunes², SILVA, Ana Carolina Nascimento ${ }^{3}$, ALVES, Danilo Gonçalves ${ }^{4}$

VIVONI, Sandra Mara Nunes. Et al. O lúdico como forma de trabalhar as inteligências múltiplas: um estudo de caso com crianças e adolescentes moradores de área de vulnerabilidade social. Revista Científica Multidisciplinar Núcleo do Conhecimento. Ano. 06, Ed. 10, Vol. 07, pp. 179-197. Outubro 2021. ISSN: 2448-0959, Link de acesso: https://www.nucleodoconhecimento.com.br/educacao/trabalhar-as-inteligencias, DOI: 10.32749/nucleodoconhecimento.com.br/educacao/trabalhar-as-inteligencias

\section{RESUMO}

Este artigo relata o estudo de caso do Projeto Social Crescendo com Manguinhos, do grupo Somar (grupo socioambiental), de Bio-Manguinhos/Fiocruz, que atua desde 2008 com ações sociais educacionais para o fortalecimento de práticas socioambientais. Uma de suas iniciativas é o Projeto Geração Manguinhos, cuja proposta pedagógica foi reformulada em 2018 e implementada em 2019, é uma ação que propõe uma metodologia participativa, sob a luz da teoria das inteligências

\footnotetext{
${ }^{1}$ Doutorado em Sociologia, Mestrado Multidisciplinar em Desenvolvimento Local, Pós-Graduada em Psicopedagogia e Docência do Ensino Superior, Graduada em Pedagogia. ORCID: https://orcid.org/0000-00019395-1064

${ }^{2}$ Graduação em Tecnologia da Informação e Pedagogia, Pós-graduada em Neurociência Pedagógica. ORCID: https://orcid.org/0000-0001-7107-8516

3 Pedagoga e MBA em Gestão Empresarial. ORCID: 0000-0002-9098-5821

${ }^{4}$ Graduação em Licenciatura/Bacharel em Educação Física / Pós-Graduado em Saúde da Família. ORCID: 00000002-8091-3576
}

RC: 99862

Disponível em: https://www.nucleodoconhecimento.com.br/educacao/trabalhar-asinteligencias 
múltiplas relacionadas à neurociência e à forma lúdica, para formação de cidadãos conscientes dos seus direitos e deveres e capazes de promover transformações sociais. O projeto visa contribuir para a formação cidadã de crianças e adolescentes da Comunidade de Manguinhos, no Rio de Janeiro, Brasil, possibilitando-Ihes uma participação mais atuante no desenvolvimento socioeconômico sustentável de sua localidade. A situação-problema proposta neste artigo é mostrar como o incentivo ao desenvolvimento das inteligências múltiplas, de forma lúdica, estimula a criatividade e muitas vezes desenvolve novas habilidades e talentos. O objetivo deste trabalho, portanto, é apresentar possibilidades de investir em práticas pedagógicas mais significativas, sobretudo de forma fundamentada e embasada com a teoria das inteligências múltiplas. A metodologia utilizada foi a pesquisa bibliográfica e a apresentação do referido projeto, que se revela um caso de sucesso que já atendeu cerca de 300 crianças e adolescentes, que têm participação ativa nos eventos, apresentam comparativos significantes do antes e depois no que se refere ao desempenho escolar e que têm atuado como protagonistas em ações em prol do próprio território. Assim, como considerações finais, observou-se que há necessidade de formar o professor no viés da ludicidade e da neurociência, vislumbrando-se um cenário cada vez mais promissor para os atores envolvidos, com a valorização das inteligências múltiplas, para que se possa reproduzir esses resultados em outros ambientes de vulnerabilidade social.

Palavras-chave: Inteligência, Neurociência, Ludicidade, Projeto social.

\section{INTRODUÇÃO}

É relevante refletir sobre as múltiplas inteligências e a neurociência associadas ao estudo da ludicidade, a partir de uma fundamentação teórica e da prática de um estudo de caso, para que, assim, apontem-se caminhos que podem ser percorridos, visando a um trabalho de qualidade. Este artigo fundamenta-se na experiência vivenciada em um projeto de responsabilidade socioambiental de BioManguinhos/Fiocruz, cujo foco são ações sociais educacionais para o fortalecimento de práticas socioambientais, que tem obtido bons resultados utilizando as múltiplas

RC: 99862

Disponível em: https://www.nucleodoconhecimento.com.br/educacao/trabalhar-asinteligencias 
inteligências relacionadas à neurociência e à forma lúdica, e que será mais bem explicado na seção três deste artigo. A situação-problema proposta neste estudo é, assim, mostrar como o incentivo ao desenvolvimento das inteligências múltiplas de forma lúdica estimula a criatividade e muitas vezes desenvolve novas habilidades e talentos nos alunos. Desse modo, o objetivo deste artigo é apresentar possibilidades de investir em práticas pedagógicas mais significativas, sobretudo de forma fundamentada e embasada com a teoria das inteligências múltiplas.

Quanto à metodologia utilizada, optou-se pela pesquisa bibliográfica, em que foram consultadas várias literaturas relacionadas às inteligências múltiplas, às neurociências e, sobretudo, à ludicidade, que foi apresentada a partir de estudo de caso de uma prática realizada em um projeto social em uma área de vulnerabilidade social. Dentre os autores consultados, estão Howard Gardner (1994; 2000), no que se refere às Inteligências Múltiplas; e Siegel e Bryson (2015), voltados para o cérebro da criança. A pesquisa bibliográfica, segundo Lakatos e Marconi (2003), tem por objetivo levar ao conhecimento do pesquisador conteúdos sobre um determinado tema, com o intuito de auxiliá-lo no estudo de suas pesquisas ou na utilização de suas informações, reforçando-se aqui a importância da pesquisa. Ainda segundo as autoras, todas as ciências caracterizam-se pela utilização de métodos científicos; em contrapartida, nem todos os ramos de estudo que empregam estes métodos são ciências (LAKATOS e MARCONI, 2003).

O acesso ao planejamento e à proposta pedagógica do projeto social que trabalha com as inteligências múltiplas serviram como estudo de caso, esclarecendo formas práticas de potencializar as diversas inteligências. Na primeira seção, está ressaltado como Gardner (1994; 2000) percebe as inteligências, o seu conceito reformulado e como caracteriza cada inteligência. Na segunda seção, é apresentada a importância do resultado da atividade lúdica, todo o movimento vivido a partir de uma ação, de uma fantasia e não o produto em si, além de defender o jogo como algo essencial para a vida. E na terceira seção, encontra-se a apresentação do estudo de caso, de uma atividade de um projeto social realizado em uma 
comunidade do Rio de Janeiro, Brasil, que contempla, de forma prática, a teoria estudada, seguida de referências e anexos.

\section{O CONCEITO REFORMULADO DAS INTELIGÊNCIAS MÚLTIPLAS E SUA RELAÇÃO COM A NEUROCIÊNCIA}

A inteligência foi encarada por Howard Gardner (2000) como um espectro de competências, algo multifacetado, assim como um cristal que poderá sofrer polimentos, intensificando cada vez mais o seu brilho. Com uma visão pluralista, o autor define inteligência como a capacidade de resolver problemas ou de criar produtos, que sejam valorizados dentro de um ou mais cenários culturais. Não nega a herança biológica, mas não a considera como ponto determinante de um sujeito, pois, segundo ele, todas as inteligências poderão e deverão ser desenvolvidas. Valoriza a educação, mas uma educação completa, levando-se em conta um sujeito possuidor de um espectro de inteligências a serem desenvolvidas de tal forma que o tornam um ser integral.

Assim, Gardner vê cada pessoa como sujeito ímpar, que tem forças cognitivas diferentes, aprende de forma e estilo diferentes de outros sujeitos, oriundos inclusive de uma mesma sociedade ou do mesmo meio cultural (GARDNER, 2000). Os testes desenvolvidos objetivando medir a inteligência humana eram, outrora, em geral, mais fundamentados no raciocínio lógico-matemático que em outra competência cognitiva. Apenas a partir da década de 1970 passou-se a discutir com maior veemência o fato de os testes mensurarem somente apenas o grau de relação com a cultura e língua dos Estados Unidos, porém não a inteligência pessoal (GARDNER, 1994).

Outro fator importante é a independência entre as inteligências. Uma pessoa, com muita habilidade em uma das competências, pode ser uma possível carente de habilidade em outras áreas. De acordo com Gardner (2000), uma das características mais importantes é que a inteligência não é um ente no interior do cérebro, mas uma competência humana realizada cerebralmente. Segundo o autor (2000), somos

RC: 99862

Disponível em: https://www.nucleodoconhecimento.com.br/educacao/trabalhar-asinteligencias 
todos inteligentes, apresentando mais êxito em determinadas circunstâncias. Assim, a concepção de inteligência, consoante seu diagnóstico, está intimamente relacionada à condição cultural.

Mesmo não sendo uma regra geral, a habilidade em uma competência não implica habilidade em todo o espectro, portanto a pessoa pode e deve ser estimulada e desenvolvida nas demais competências. Embora exista independência entre as diferentes inteligências, elas interagem. Gardner (2000) estabeleceu critérios, segundo os quais é possível medir se um talento é realmente uma inteligência. Cada inteligência deve ter uma característica de desenvolvimento, ser passível de observação, com pessoas-prodígios ou não, e proporcionar alguma evidência de localização no cérebro. Embora a maior parte das pessoas possuam todo o espectro das inteligências, cada indivíduo revela características cognitivas distintas. Possuímos quantidades variadas das oito inteligências elencadas por Gardner, e as combinamos e usamos de maneiras extremamente pessoais.

A pesquisa de Gardner (2000) não só revelou um grupo mais amplo de inteligências humanas do que previamente se conhecia, mas também gerou uma definição pragmática renovadora do conceito de inteligência. Esse é um conceito reformulado, pois o autor pensa em inteligência como uma fita elástica indo além da solução de problemas existentes, e olha mais para a capacidade produtiva do ser humano de produzir objetos, como obras de arte e experiências científicas, aulas, planejamento, que exijam uma ou mais inteligências.

Campbell; Campbell e Dickinson (2000) listaram as diversas inteligências com exemplos para melhor entendimento. A inteligência verbal linguística, por exemplo, está voltada para o aspecto persuasivo da linguagem ou a capacidade de convencer as outras pessoas de um determinado curso da ação. A palavra falada possibilitou aos nossos ancestrais passarem do pensamento concreto para o pensamento abstrato, à medida que progrediram da indicação dos objetos para sua nomeação e referência a eles em sua ausência. A leitura possibilitou aos seres humanos conhecer objetos e lugares, processos e conceitos. A escrita possibilitou a 
comunicação, e é a partir da habilidade de pensar com as palavras que os seres humanos podem lembrar, analisar, resolver problemas, planejar o futuro e criar.

Bebês que ouviram histórias, canções e conversas antes do seu nascimento têm início precoce no desenvolvimento da inteligência linguística (CAMPBELL; CAMPBELL e DICKINSON, 2000). Por isso, a importância de criar ambientes ricos em linguagem, incluindo brincar com palavras, contar histórias, fazer perguntas, declarar opiniões e estimular a curiosidade. O desenvolvimento desses quatro componentes da inteligência verbal linguística, leitura e escrita, escuta e fala, pode ter um efeito importante sobre o sucesso na aprendizagem de qualquer disciplina durante toda a vida. Assim, provavelmente uma pessoa possuidora da Inteligência verbal linguística bem desenvolvida possa escutar e responder ao som, ao ritmo, à cor e à variedade da palavra falada, imitar os sons da linguagem, a leitura e a escrita dos outros, aprender a partir da escuta, leitura escrita e discussão, escutar eficientemente, compreender, parafrasear, recordar o que foi dito, ler eficientemente, compreender, resumir, interpretar, exibir habilidade para aprender outros idiomas, refletir sobre a própria linguagem, entre outras habilidades linguísticas.

Outra inteligência deste espectro é a lógico-matemática. Esta envolve vários componentes, como cálculos matemáticos, raciocínio lógico, resolução de problemas, raciocínios dedutivo e indutivo e discernimento de padrões e relacionamentos. No centro da capacidade matemática está a capacidade de reconhecer e resolver problemas, abrangendo os campos da matemática, ciência e lógica. Uma pessoa com essa inteligência desenvolvida reconhece os objetos e sua função no ambiente, está familiarizada com os conceitos de quantidade, tempo, causa e efeito; usa símbolos abstratos para representar objetos e conceitos concretos; demonstra habilidade na resolução de problemas lógicos; percebe padrões e relacionamentos; levanta e testa hipóteses; usa diversas habilidades matemáticas, como realizar estimativas, cálculos de algoritmos, interpretação de estatística e representação visual de informações em forma gráfica; operações complexas como cálculo, física, programar; pensa matematicamente reunindo as evidências, criando hipóteses, formulando modelos, usando a tecnologia para 
resolver problemas matemáticos; expressa interesse por carreiras como contabilidade, tecnologia de computação, direito, engenharia e química; cria novos modelos ou faz novas descobertas em ciência ou matemática (CAMPBELL; CAMPBELL e DICKINSON, 2000).

A aprendizagem deve envolver os alunos tanto intelectual quanto fisicamente. Eles devem tornar-se aprendizes ativos, desafiados a aplicar seu conhecimento prévio e passar por situações novas e cada vez mais complexas, por isso as abordagens de ensino devem envolver os alunos no processo de aprendizagem e não apenas lhes transmitir informação.

A inteligência musical trabalha com uma linguagem que usa três componentes básicos, som, ritmos e timbres, e é frequentemente escrita com sistemas simbólicos próprios. As inúmeras combinações desses três elementos deram origem à enorme variedade de música encontrada em todo mundo. Howard Gardner (1994) afirma que qualquer indivíduo normal que teve uma exposição frequente à música pode manipular o som, o ritmo e o timbre para participar com alguma habilidade de atividades musicais, incluindo a composição, o canto ou a execução de instrumentos. A música em sala de aula pode ajudar a formar um ambiente positivo que desencadeia a aprendizagem, e há alunos que têm uma capacidade musical maior que outros. Como diz o autor, o talento musical emerge inexplicavelmente mais cedo do que outros dons em outras áreas da Inteligência humana.

É provável que uma pessoa com a inteligência musical bem desenvolvida ouça e responda com interesse a uma variedade de sons, incluindo a voz humana, os sons ambientais e a música, e organize esses sons em padrões significativos; aprecie e busque oportunidades para ouvir música ou sons ambientais no meio de aprendizagem, avaliando e explorando o conteúdo e o significado da música; reconheça e discuta diferentes estilos e gêneros musicais e variações culturais; demonstre interesse no papel que a música tem desempenhado e continua a desempenhar nas vidas humanas; colecione canções e informações sobre a música de várias formas, tanto gravadas quando impressas, e até colecione e execute 
instrumentos musicais, incluindo pesquisadores; desenvolva a capacidade para cantar e/ou tocar um instrumento, sozinho ou com outras pessoas; use o vocabulário e as notações da música; desenvolva uma estrutura pessoal de referência para ouvir música; aprecie improvisar e brincar com os sons e, ao ouvir um segmento musical, possa completar uma frase de modo que faça sentido; possa apresentar sua própria interpretação do que um compositor está comunicando por meio da música e também analisar e criticar as peças musicais; expresse interesse em profissões que envolvam a música, como ser cantor, instrumentista, engenheiro de som, produtor, crítico, fabricante de instrumentos, professor ou regente; possa criar composições e/ou instrumentos musicais originais (GARDNER, 1994).

A inteligência espacial foi uma inteligência que esperou os primeiros registros dos desenhos humanos, pois durante a era glacial, entre 60.000 e 10.000 a.C., os habitantes das cavernas na França, Espanha, África e Escandinávia pintaram figuras de animais e cenas de sua própria experiência (CAMPBELL; CAMPBELL e DICKINSON, 2000). A linguagem desenvolveu-se a partir das imagens para pictogramas e daí para códigos simbólicos, tornando-se cada vez mais abstrata. A inteligência visual espacial inclui várias habilidades relacionadas, como discriminação visual, reconhecimento, projeção, imagens mentais, raciocínio espacial, manipulação de imagens, qualquer delas podendo ser expressa por uma única pessoa.

Nas salas de aula, os alunos visualmente capazes são estimulados quando o humor visual faz parte do ambiente com caricaturas, cartazes espirituosos e gravuras humorísticas ou fotografias relacionadas à matéria que está sendo estudada. É provável que uma pessoa com uma inteligência visiospacial bem desenvolvida aprenda por meio da visão e da observação. Reconheça fisionomias, objetos, formas, cores, detalhes e cenas; navegue o seu eu e os objetos efetivamente pelo espaço, como ao movimentar-se através de aberturas, encontrar a saída de uma floresta sem uma trilha, dirigir um automóvel pelo tráfego ou remar uma canoa em um rio; perceba e produza imagens mentais, pense por meio de imagens e visualize detalhes visuais como auxílio para recordar informações; decodifique gráficos, RC: 99862

Disponível em: https://www.nucleodoconhecimento.com.br/educacao/trabalhar-asinteligencias 
tabelas, mapas e diagramas. Aprenda por meio de representação gráfica ou meios visuais; goste de rabiscar, desenhar, pintar, esculpir ou reproduzir de qualquer outro modo objetos em formas visíveis; goste de construir produtos tridimensionais, como objetos de origami, pontes e casas de brinquedo; é capaz de mudar mentalmente a forma de um objeto como, por exemplo, dobrar uma folha de papel até transformá-la em uma forma complexa e visualizar sua nova forma, ou mentalmente mover os objetos no espaço para determinar como eles interagem com outros objetos, como engrenagens que fazem parte de uma máquina; veja as coisas de maneiras diferentes ou a partir de "novas perspectivas", como o espaço negativo em torno de uma forma, ou detecte uma forma "oculta" em outra; perceba tanto padrões óbvios como padrões sutis; representação concreta ou visual da informação; seja na projeção representativa ou abstrata; expresse interesse ou aptidão para ser um artista, fotógrafo, engenheiro, artista gráfico, arquiteto, designer, crítico de artes, piloto ou outras opções que exijam habilidades visuais (GARDNER, 1994).

A inteligência cinestésica envolve todo o corpo em suas atividades ou prefere trabalhar com situações concretas. Esta Inteligência é observada em atores, atletas, dançarinos, mecânicos e joalheiros. A pessoa cinestésica corporal é a base do conhecimento humano, pois é por meio de nossas experiências sensório-motoras que experimentamos a vida. Porém, ter habilidade em um domínio cinestésico não indica talento em outro. Uma pessoa com inteligência cinestésica bem desenvolvida normalmente investiga o ambiente e os objetos por meio do toque, do experimento. Prefere tocar, manejar ou manipular o que deve ser aprendido; desenvolve a coordenação, um senso de ritmo; aprende melhor pelo envolvimento e a participação direta; lembra-se mais claramente do que foi feito do que o que foi dito ou observado; gosta de experiências de aprendizagem concretas, como viagens de campo, construção de modelos ou participação em representações, jogos, reunião de objetos diretos ou exercícios físicos; mostra destreza no trabalho realizado com movimentos motores restritos ou amplos; é sensível e reage a ambientes e sistemas físicos; demonstra habilidade para representação, atletismo, dança, costura, escultura; demonstra equilíbrio, graça, destreza e precisão nas tarefas físicas; tem 
habilidade para aprimorar e aperfeiçoar o desempenho físico pela integração entre o corpo e a mente; compreende e vive segundo padrões fisicamente saudáveis; pode expressar interesse por profissões como atletas, dançarinos, cirurgião ou construtor; inventa novas abordagens para as habilidades físicas ou cria novas formas na dança, no esporte ou em outras atividades físicas (GARDNER, 1994).

A inteligência interpessoal permite-nos compreender as outras pessoas e comunicarmo-nos; assim, alunos com habilidades interpessoais apreciam contato com pessoas da mesma faixa etária e alguns são sensíveis aos sentimentos dos demais, frequentemente ajudam, apreciam valores e opiniões diferentes. É provável que uma pessoa com a inteligência interpessoal bem desenvolvida seja ligada aos pais e interaja com outras pessoas; forme e mantenha relacionamentos sociais; reconheça e use várias maneiras de se relacionar com as outras pessoas; perceba os sentimentos, os pensamentos, os comportamentos e os estilos de vida das outras pessoas; participe de esforços cooperativos e assume várias papéis adequados, desde deixar conduzir até liderar atividades em grupo; influencie as opiniões ou as ações das outras pessoas; adapte o comportamento a diferentes ambientes ou grupos e a partir de informações de outras pessoas; perceba perspectivas diferentes em qualquer questão social ou política; desenvolva habilidades de mediação, organizando outras pessoas para uma causa comum ou trabalhando com outras pessoas de diferentes idades ou origens; expresse interesse por profissões voltadas para as relações interpessoais, como ensino, o trabalho social, o aconselhamento, o gerenciamento ou a política; desenvolva novos processos ou modelos sociais.

$\mathrm{Na}$ inteligência intrapessoal encontramos qualidades como motivação, determinação, ética, integridade, empatia e altruísmo. Sem esses recursos internos é difícil viver uma vida produtiva. A maioria dos pesquisadores acredita que assim que chegamos ao mundo as inteligências pessoais já estão se desenvolvendo a partir de uma combinação de hereditariedade, ambiente e experiência. Esta inteligência inclui nossos pensamentos e sentimentos e, assim, quanto mais pudermos trazê-la à consciência, melhor poderemos relacionar nosso mundo interior com o exterior. Quando nos descobrimos fazendo algo de forma automática, RC: 99862

Disponível em: https://www.nucleodoconhecimento.com.br/educacao/trabalhar-asinteligencias 
devemos parar e recomeçar de maneira ponderada, observando o nosso comportamento (GARDNER, 1994).

Provavelmente uma pessoa com a inteligência intrapessoal bem desenvolvida tenha consciência de sua gama de emoções; encontre abordagens e modos de expressar seus sentimentos e pensamentos; desenvolva um modelo preciso de sua identidade; seja motivada a definir e lutar por seus objetivos; estabeleça-se e viva segundo o sistema de valores éticos; lute pela autorrealização e estimule outras pessoas.

Quanto à inteligência naturalista, Gardner (1994) define como alguém que é capaz de reconhecer a fauna e a flora e fazer distinções coerentes no mundo natural. $O$ naturalista geralmente é hábil em identificar membros de um grupo ou espécie. Todos usamos as habilidades da inteligência naturalista quando identificamos pessoas, plantas, animais e outras características do nosso ambiente. É provável que uma pessoa com a inteligência naturalista bem desenvolvida explore os ambientes humano e natural com interesse e entusiasmo; procure oportunidades para observar, identificar, interagir ou cuidar de objetos, plantas ou animais; categorize ou classifique os objetos segundo suas características; reconheça padrões entre os membros de uma espécie ou classe de objetos; procure aprender sobre os ciclos de vida da flora ou fauna ou sobre a produção de objetos feitos pelo homem; queira entender "como as coisas funcionam"; seja interessada em saber como os sistemas mudam e se desenvolvem; mostre interesse no relacionamento entre as espécies, aprenda a taxonomia para as plantas e os animais ou outros sistemas de classificação; possa mostrar interesse em profissões como biologia, ecologia, química, zoologia, silvicultura ou botânica e desenvolva novas taxonomias, teorias dos ciclos de vida ou revele novos padrões e interconexões entre objetos ou sistemas.

A inteligência existencial, conhecida como inteligência espiritual ou transcendental (GARDNER, 2000), se refere a aspectos existenciais do ser humano, como quem somos, o que ocorre depois da morte, entre outros. A carência de valores espirituais está acarretando grandes crises existenciais, pessoais e sociais, que colocam em

RC: 99862

Disponível em: https://www.nucleodoconhecimento.com.br/educacao/trabalhar-asinteligencias 
evidência a necessidade urgente de fomentar este tipo de inteligência na sociedade, com intuito de recuperar uma visão muito mais profunda sobre o ser humano e a vida. Essa inteligência apresenta algumas características marcantes, como interesses pela origem da vida e o sentido da morte e nossa existência; transcendência do físico e experiência de todos os elementos do universo como um todo; defende valores universais, como paz, amor, sabedoria, bondade, verdade, paternidade, curiosidade, interesse por conhecimentos e práticas espirituais; anseio de servir e ajudar os outros; necessidade de cuidado pessoal e de agir em consenso com o restante das pessoas durante uma tomada de decisão; executa ações solidárias, respeitosas, cuidadosas e pacíficas. A necessidade da inteligência existencial torna-se imprescindível atualmente, como meio para combater a falta de valores que domina nossa sociedade, que originou uma pobreza espiritual global causada pelos males do nosso mundo.

Howard Gardner (1994) reconheceu que a cognição humana é amparada em oito modos diferentes de inteligência que todas as pessoas possuem, porém em graus diferentes, e relacionou cada uma dessas inteligências a distintas estruturas cerebrais; ademais, o autor apresenta uma definição de inteligência como a competência de solucionar problemas ou conceber itens de valor em uma cultura ou sociedade.

A inteligência lógico-matemática está presente na facilidade de raciocínio lógico e em enxergar soluções de problemas matemáticos, e está localizada no lobo do parietal esquerdo e em áreas de associação temporal e occipital adjacente, no hemisfério esquerdo para designação verbal, no hemisfério direito para ordenação espacial, e o sistema frontal para organizar e definir metas.

A inteligência linguística surge aos dois anos, se desenvolve com o tempo em sua forma mais completa, e está localizada na área da broca, presente no córtex frontal esquerdo, área de Wernicke no lobo temporal esquerdo, sulco lateral na parte interior do lobo parietal. A inteligência espacial aparece em pessoas com bom sentido de localização, e a área neural apontada são o lobo occipital e a parte 
posterior do lobo parietal direito. Localizado no lobo frontal e na parte anterior ao lobo temporal direito, a musicalidade está presente nessa inteligência, assim como a capacidade de obedecer a ordens, pessoas com entonação de voz, ritmo e sensibilidade emocional à música.

A inteligência corporal-cinestésica é a capacidade de resolver problemas ou elaborar produtos utilizando o corpo inteiro ou partes, e está presente na área motora, tálamo, gânglios basais e cerebelo.

As principais teorias acerca da inteligência são que há uma inteligência geral ou outros tipos de inteligência (fluida e cristalizada) (CATELL, 1998). Apesar de algumas inteligências compartilharem áreas neuronais, nenhuma partilhou mais de três regiões referidas. Assim, o córtex frontal simbolizava cerca de $40 \%$ das referências para a inteligência musical e para a inteligência intrapessoal, o que pode acarretar uma semelhança neural das duas inteligências. Porém, um estudo mais detalhado demonstrou que na inteligência musical os parâmetros sobre o córtex frontal eram específicos para o córtex motor, enquanto na inteligência intrapessoal, os parâmetros eram específicos para o córtex pré-frontal. Ou seja, as estruturas neurais das duas inteligências eram de fato distintas. Há fortes indícios de que cada uma das oito inteligências tem sua própria arquitetura neural, maneiras comuns entre essas inteligências e, desse modo, entender essas conformações únicas e os pontos em comum poderá nos proporcionar elementos de como o cérebro organiza um amplo conjunto de informações e como ele executa práticas intelectuais. Uma questão que ainda pode permanecer em aberto é se a teoria das múltiplas inteligências pode ser utilizada como uma conexão competente entre neurociência e educação. Contudo, indica sua contínua possibilidade. Poderemos, então, estar em uma posição mais forte para aprimorar a "arte do ensino", de modo que os estudantes possam expandir seus potenciais, que são únicos, quaisquer que sejam suas aptidões.

Gardner (1994) afirma que estas inteligências se apresentam de duas formas: algumas pessoas já nascem com determinadas inteligências, ou seja, a genética

RC: 99862

Disponível em: https://www.nucleodoconhecimento.com.br/educacao/trabalhar-asinteligencias 
contribui. Porém, as experiências vividas também colaboram para o desenvolvimento de determinadas inteligências.

Os estímulos e o ambiente social são importantes no desenvolvimento de determinadas inteligências. Na próxima seção será mencionada a ludicidade e a sua importância no processo ensino-aprendizagem.

\section{O LÚDICO E A SUA IMPORTÂNCIA NA APRENDIZAGEM}

O lúdico está em todos os espaços e precisa ser trabalhado para expressar a criatividade que existe em cada aluno, a fim de oferecer a ele a oportunidade de descobrir algo de que necessita (HUIZINGA, 1996). O que importa na atividade lúdica não é o produto da atividade, e sim, o seu resultado, o momento vivido a partir de uma ação, momentos de fantasiar a realidade, a percepção, o autoconhecimento e conhecimento do outro. Huizinga (1996) ainda defende que o jogo é uma divisão definitivamente principal da vida, tão essencial quanto o raciocínio lógico, e que o elemento lúdico está na base do nascimento e acréscimo da civilização. $O$ ato de brincar vem de casa, as brincadeiras seguem a criança durante toda a infância e adentram na escola em forma de brincadeiras que socializam e ensinam a fazer parte do grupo social no qual está inserida. Para Kishimoto (1994), o jogo está vinculado à imaginação, ao modo de pensar e ao símbolo como uma fonte de linguagem que constrói de forma coletiva a capacidade de raciocinar, imaginar, recriar e conviver na busca pela qualidade pedagógica no desenvolvimento da criança.

Trabalhar ações lúdicas é atribuir a máxima importância em reconhecer e estimular as várias inteligências humanas e todas as combinações de inteligência. Segundo Gardner (1994) nós somos todos tão diferentes, em grande parte, porque possuímos diferentes combinações de inteligência. Se reconhecermos isso, poderemos ter pelo menos uma chance melhor de lidar adequadamente com os muitos problemas que enfrentamos na atualidade.

RC: 99862

Disponível em: https://www.nucleodoconhecimento.com.br/educacao/trabalhar-asinteligencias 
Para Bettelheim (1988), pela brincadeira a criança manifesta o que teria dificuldade de colocar em palavras, e a opção de suas ações é motivada por processos íntimos de sua linguagem. Portanto, para incentivar a aprendizagem o professor deve trabalhar a criatividade que induza os alunos a gostarem de aprender, para que eles percebam na prática o quanto o ensino é útil para as suas vidas. Assim, é fundamental que isso aconteça, pois desse modo a criança colocará o ensino como busca constante em sua vida.

\section{UM CASE DE SUCESSO EM ÁREA DE VULNERABILIDADE SOCIAL}

Este artigo relata uma pesquisa de campo, a partir do estudo de caso do Projeto Social Crescendo com Manguinhos, do grupo Somar (grupo socioambiental), de BioManguinhos/Fiocruz. O Instituto de Tecnologia em Imunobiológicos (BioManguinhos) é um dos maiores produtores públicos de vacinas da América Latina e tem papel estratégico para o Programa Nacional de Imunizações do Ministério da Saúde. Além de produtor e desenvolvedor de novas vacinas, Bio-Manguinhos também fabrica reagentes para diagnóstico de diversas doenças, tem a missão de auxiliar na redução da dependência tecnológica do país e já firmou diversos contratos e parcerias nesse sentido. Em 2008, foi implantada a Responsabilidade Socioambiental (Somar) com a incumbência de oferecer respostas aos múltiplos desafios vividos pela população vizinha à Fiocruz.

Uma das iniciativas da Responsabilidade Socioambiental de Bio-Manguinhos é o projeto de implementação de ações sociais educacionais para o fortalecimento de práticas socioambientais, que propõe uma metodologia participativa para formação de cidadãos conscientes dos seus direitos e deveres, capazes de promover transformações sociais. O projeto pedagógico social visa contribuir para a formação cidadã de crianças, adolescentes, jovens e adultos da Comunidade de Manguinhos, no Rio de Janeiro, Brasil, possibilitando-Ihes uma participação mais atuante no desenvolvimento socioeconômico sustentável do território.

RC: 99862

Disponível em: https://www.nucleodoconhecimento.com.br/educacao/trabalhar-asinteligencias 
As atividades ocorrem em quatro frentes de trabalho, com público-alvo de faixas etárias diferentes, que se inter-relacionam. Entre elas destaca-se o Projeto Geração Manguinhos, com suas unidades temáticas: Eu e o Mundo; Vida, Tecnologia e Sociedade; Grupos de Estudos; Espaço Ágora e Ação e Criação. E é por conta desta última unidade, cuja proposta pedagógica foi reformulada em dezembro de 2018 e implementada em 2019 e que já contou com a participação de cerca de 300 crianças e adolescentes, que este projeto virou objeto de interesse, pois trabalha a partir das inteligências múltiplas. As atividades, realizadas diariamente, e que atualmente contam com 50 participantes com idades entre 10 e 13 anos, visam ao desenvolvimento das capacidades cognitivas e empreendedoras dos participantes do projeto, em que o processo de aprendizagem tem como prioridade a contextualização da realidade.

A relação do conteúdo, com a teoria das inteligências múltiplas, desenvolvida pelo projeto da Fiocruz, vem sendo trabalhada por dois personagens mediadores, que fazem parte da equipe pedagógica, nomeados pelos participantes de "Matúscula" e "Esparadrapo" (Anexo 1), que são nomes-fantasia. Semanalmente, no sentido de criar um ambiente estimulador e lúdico ao desenvolvimento cognitivo relacionado à neurociência aplicada às práticas pedagógicas, eles se conectam emocionalmente com os participantes e redirecionam, nutrindo as ondas emocionais da mente, como afirmam Siegel e Bryson (2015).

No início do ano os professores realizam um teste para verificar a inteligência predominante dos participantes e auxiliam no processo de autoconhecimento e identificação de seus próprios potenciais, bem como de suas habilidades, além de trabalhar as eventuais dificuldades que eles possam apresentar. O incentivo ao desenvolvimento das inteligências múltiplas estimula a criatividade e muitas vezes desenvolve novas habilidades e talentos, além de contribuir com a autoestima dos participantes, como foi constatado em uma das aulas, em que uma das crianças, durante uma atividade, verbalizou não ter nenhum talento. O professor, caracterizado como o personagem "Esparadrapo", fez uso de um vídeo do Youtube, de Maurício de Souza, no qual o personagem Chico Bento é avaliado por sua RC: 99862

Disponível em: https://www.nucleodoconhecimento.com.br/educacao/trabalhar-asinteligencias 
professora por supostamente não apresentar nenhum talento[5]. Na história, a professora resolve ir à casa do personagem e descobre a sua habilidade em cuidar das plantas e dos animais, manifestando, então, a inteligência naturalista. A partir desta situação, o professor do projeto despertou no aluno um olhar apreciativo, para sua habilidade pictórica. E em seguida o aluno fez um desenho de si, de forma digital, que pode ser visualizado no Anexo 2.

Nesta perspectiva e por conta da faixa etária dos participantes, o lúdico se faz presente em todas as atividades, servindo de incentivo à participação. Os personagens favorecem o contato com as diversas inteligências e fazem a mediação das atividades que são realizadas a partir de jogos, uso de sucata, tecnologia, aquários, círculos de conversas, entrevistas, calculadoras, exercícios físicos, dança, teatro, movimentos criativos, fotografias, fluxogramas, contato com a natureza, entre outros, culminando em um show de talentos (Anexo 3).

Esta experiência pedagógica revela-se um caso de sucesso quando percebemos a participação ativa nos eventos, comparativos significantes do antes e depois no que se refere ao desempenho escolar, além do protagonismo que se destaca nas ações em prol do próprio território, como, por exemplo, a contribuição de um jovem ajudando outras crianças menos favorecidas a realizar suas tarefas escolares.

\section{CONSIDERAÇÕES FINAIS}

Faz-se necessário conhecer como a mente do nosso aluno funciona, pois mesmo não sendo uma regra geral, a habilidade em uma competência não implica habilidade em todo o espectro, portanto esta pessoa pode e deve ser estimulada e desenvolvida nas demais competências.

Embora exista independência entre as diferentes inteligências, estas interagem. Gardner (1994) estabeleceu critérios, segundo os quais é possível medir se um talento é realmente uma inteligência. Cada inteligência deve ter uma característica de desenvolvimento, ser passível de observação, com pessoas- prodígio ou não, e 
proporcionar alguma evidência de localização no cérebro. Embora a maior parte das pessoas possuam todo o espectro das inteligências, cada indivíduo revela características cognitivas distintas. Possuímos quantidades variadas das oito inteligências e as combinamos e usamos de maneiras extremamente pessoais. A pesquisa de Gardner não só revelou um grupo mais amplo de inteligências humanas do que previamente se conhecia, mas também gerou uma definição pragmática renovadora do conceito de inteligência.

A experiência positiva com as crianças e adolescentes do projeto Geração Manguinhos demonstra a importância de professores capazes de trabalhar as inteligências múltiplas com viés da ludicidade, em especial em cenários de vulnerabilidade social, pois podem despertar nos alunos a autoestima, melhora no desempenho escolar e até mesmo atuação como protagonistas em ações em prol da própria localidade.

Portanto, investir em práticas pedagógicas mais significativas, sobretudo de forma fundamentada e embasada com a neurociência, sem esgotar a constante pesquisa, poderá levar a um ensino de qualidade, como vem fazendo o projeto social Crescendo com Manguinhos em uma área de vulnerabilidade social, apesar dos desafios encontrados.

\section{REFERÊNCIAS}

BETTELHEIM, Bruno. Uma vida para seu filho, $2^{\mathrm{a}}$ ed. Rio de Janeiro: Editora Campus, 1988, 360 p., ISBN 9788570015297.

CAMPBELL, Linda; CAMPBELL, Bruce; DICKINSON, Dee. Ensino e Aprendizagem por meio das Inteligências Múltiplas, $2^{a}$ ed., Porto Alegre: Artmed, 2000, 308 p., ISBN: 9788573075120.

CATTELL, R. B. Where Is Intelligence? Some Answers From The Triadic Theory. In J. J Mcardle \& R. W. Woodcock (Orgs.), Human Cognitive Abilities In Theory And Practice. New Jersey: Erlbaum, 1998, pp. 29-38.

RC: 99862

Disponível em: https://www.nucleodoconhecimento.com.br/educacao/trabalhar-asinteligencias 
GARDNER, Howard. Estruturas da mente. A teoria das inteligências múltiplas, 1ํㅡㄹ., Porto Alegre: Editora Artes Médicas, 1994, 340 p., ISBN: 8573073462.

GARDNER, Howard. Inteligência, um conceito reformulado, $1^{\underline{a}}$ ed. Rio de Janeiro: Editora Objetiva, 2000, 348 p., ISBN: 9788573023213.

HUIZINGA, Johan. Homo Ludens - O jogo como elemento da cultura. São Paulo: Editora Perspectiva, 1996, 304 p., ISBN 8527311577.

KISHIMOTO, Tizuko Morchida. 0 jogo e a educação infantil, $1^{\text {a }}$ ed. São Paulo: Pioneira, 1994, 62 p., ISBN 9788522101276.

LAKATOS, Eva Maria; MARCONI, Marina de Andrade. Fundamentos de metodologia científica, 5ª ed. São Paulo: Atlas, 2003, 310 p. ISBN: 85-224-3397-6.

SIEGEL, Daniel; BRYSON, Tina Payne. O Cérebro da Criança: Estratégias Revolucionárias para nutrir a mente em desenvolvimento do seu filho e ajudar sua família a prosperar, 1a. Edição. São Paulo: nVersos, 2015, 240p, ISBN 8584440739 . 


\section{ANEXOS}

Anexo 1

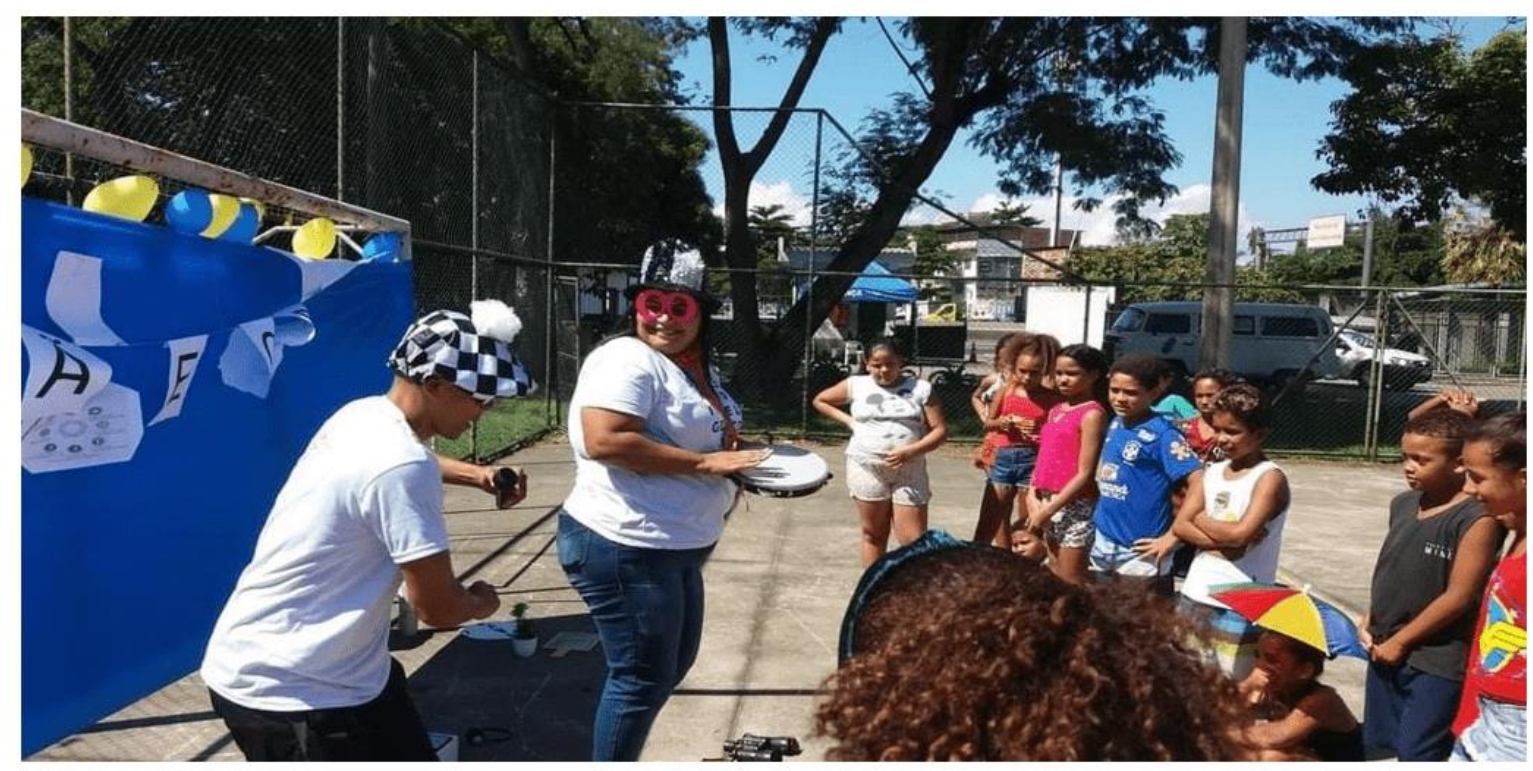

"Matúscula", "Esparadrapo" e algumas crianças do projeto.

Anexo 2

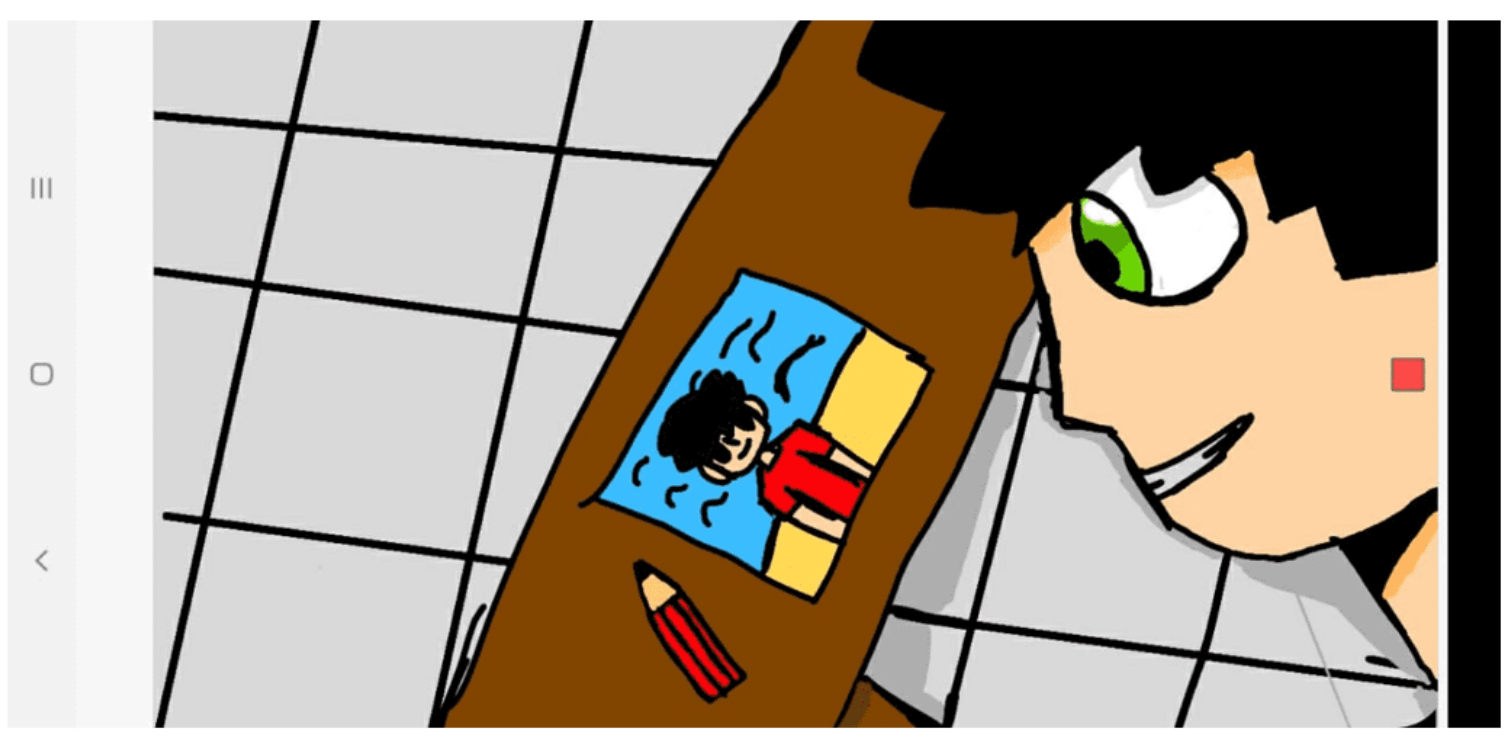

Desenho de um dos alunos.

RC: 99862

Disponível em: https://www.nucleodoconhecimento.com.br/educacao/trabalhar-asinteligencias 
Anexo 3

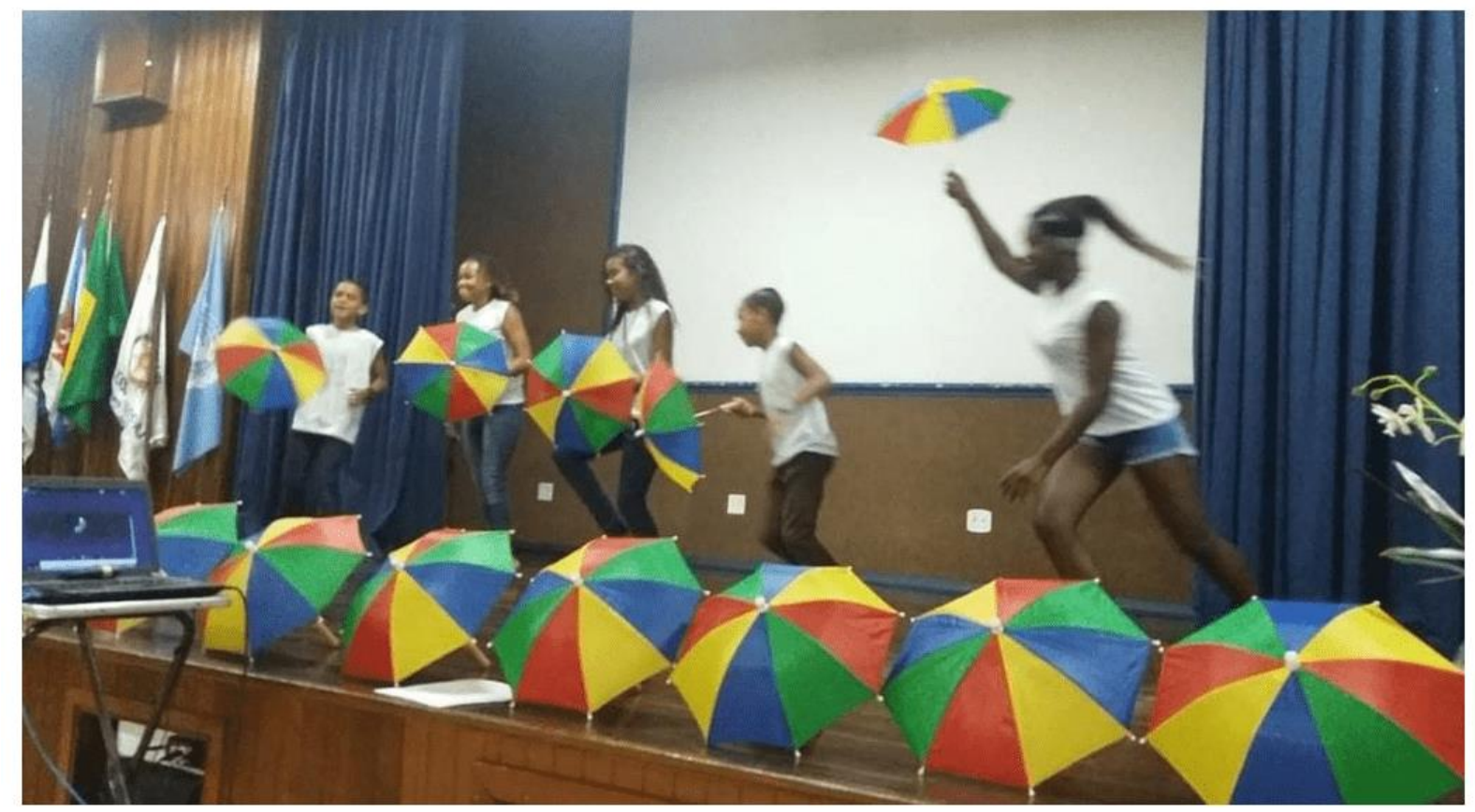

Show de talentos.

\section{APÊNDICE- REFERÊNCIA NOTA DE RODAPÉ}

[5] Disponível em: https://www.youtube.com/watch?v=x8sMdtVEiUw. Acesso em 25 de julho de 2021.

Enviado: Setembro, 2021.

Aprovado: Outubro, 2021.

RC: 99862

Disponível em: https://www.nucleodoconhecimento.com.br/educacao/trabalhar-asinteligencias 